\title{
Leucocitos fecales en el sindrome diarreico agudo del lactante
}

Dra. Fossanna Lagos Z., ${ }^{1}$ Dr. Gastón Duffau T. ${ }^{2}$ y Carlos Navarrete M. ${ }^{3}$

Investigation of fecal leukocytes in the acute diarrheic syndrome of the infant

\begin{abstract}
The presence of leukoxytes was investigated in the feces of 223 hospitalized patients at the Infants Department of the Hoberto del Rio Hospital. The findings were corre lated with clinical and bacteriological parameters.

There were positive findings in 51 patients $(24,2 \%$ ) that showed a highly significant frecuency of cases that coursed with fever, blood or mucus in the feces, periods of hospitalization of more than 7 days and isolation of Shigella and Salmonello.

There was no difference in debydration nor in the frecuency of E. Coli classic seratypes.

The technique used for cell investigation is described, as also the results of the daily follow-up in the positives cases.

Investigation of feeal leukocytes in patients with diarthea gives valuable aethiopathogenic and prognostic information.
\end{abstract}

La eliminación de leucocitos en las heces, manifestación de un proceso inflamatorio de la mucosa intestinal distal, ha despertado el interés de varios autores por establecer su asociación con cuadros diarreicos de etiología invasora. ${ }^{1-8}$ Aun-

\footnotetext{
${ }^{1}$ Becada de $1^{\circ}$ Año Pediatría, Hosp. R. del Río.

2 Servicio Lactantes, Hosp. F. del Río.

${ }^{3}$ Alumno $7^{\circ}$ Año de Medicina Facultad de Medicina Sede Norte. Ciniversidad de Chile.
}

que su valor como elemento de aproximación precoz al diagnóstico etiológico del Síndrome Diarreico Agudo no ha sido claramente demostrado, a nuestro juicio, la presencia de leucocitos fecales refleja una característica patogénica importante que permite distinguir dos poblaciones entre los pacientes con diarrea: aquella en la cual la enfermedad cursa con un proceso inflamatorio $y$ alteraciones anatómicas secundarias del intestino y otra cuya etiología no condiciona un daño orgánico 
evidenciable con la investigación de leucocitos.

La variabilidad del Sindrome Diarreico Agudo del Lactante en relación a la gravedad de presentación del cuadro clínico y las diferencias frecuentemente observadas ea su evolución, nos motivóa estudiar en forma comparativa los pacientes hospitalizados con este diagnóstico, con el propósito de determinar si la presencia de leucocitos fecales se acompaña o no de diferencias significativas en la intensidad de las manifestaciones clínicas al ingreso y en el comportamiento de la enfermedad durante la evolución intrahospitalaria. A nuestro parecer esto constituiría una prueba a favor de que los leucocitos fecales pueden considerarse un elemento con valor pronóstico en el Sindrome Diarreico Agudo del Lactante.

\section{MATERIAL Y METODO}

Se estudiaron 243 casos de pacientes ingresados al Servicio de Lactantes del Hospital Roberto del Río, con diagnóstico de Síndrome Díarreico Agudo. Dentro de las primeras 24 horas de hospitalización se tomó una muestra para investigación de leucocitos fecales. Esta última fue extraída directamente por estimulación anal y conservada en refrigeración hasta su análisis, por un periodo no superior a $\mathbf{4 8}$ horas. Se hizo extendidos delgados sobre placas de vidrio, especialmente de las zonas de mucus o pus y se tiño con técnica de MayGrunwald-Giemsa para posterior examen en mi croscopio de luz bajo aceite de inmersión.

En los casos en que se encontraron leucocitos, el examen se repitió cada 24 horas hasta que se observó la desaparición de las células en las nuestras de 2 días sucesivos.

En 80 casos se tomaron 3 muestras separadas por un intervalo de 3 a 4 horas durante el curso de un mismo día, para comparar el rendimiento del método.

La extracción, procesamiento y lectura de todas las muestras, fue realizada por la misma persona, en desconocimiento de la historia clínica de los pacientes.

Se eligió la tinción de M.G.G. por ser una técnica sencilla que ofrece ventajas sobre el Azul de Metileno brindando una mejor fijacion y una tincíón policromática que facilita la identificación de los elementos celulares.

Paralelamente al estudio de laboratorio, un segundo investigador recolectó los siguientes datos de las historias clínicas de los pacientes:
- Grado de deshidratación al ingreso (porcentaje de ganancia de peso una vez corregida la hidratación).

- Temperatura al ingreso.

- Presencia de mucus o sangre en las deposiciones.

- Número de días de estadía hospitalaria.

- Aislamiento de Salmonella o Shiguella durante la primera semana de hospitalización.

- Aislamiento de E. Coli enteropatógeno durante la primera semana de hospitalización.

\section{RESULTADOS}

En el período comprendido entre el 20 de tebrero y el 28 de agosto de 1981 se estudiaron 243 pacientes cuyo principal diagnóstico de ingreso fue Sindrome Diarreico Agudo. Se excluyeron de la investigación 10 casos con antecedentes insuficientes y 10 en los que la evolución clínica obligó a descartar el planteamiento diagnóstico inicial, antes de cumplido el tercer día de hospitalizacion: 3 Bronconeumonias, 3 Fiebre Tifoidea, 2 Meningitis, 1 Invaginación intestinal y 1 Pielonefritis.

Se encontraron leucocitos en 54 muestras fecales obtenidas el primer día de hospitalización. De acuerdo a la positividad del examen y sin considerar las variaciones morfológicas ni cuantitativas de las células, se clasificaron los pacientes en dos grupos:

A: con leucocitos ( 54 pacientes)

B: sin leucocitos (169 pacientes)

Ambas poblaciones resultaron comparables en cuanto a edad, sexo y estado nutricional (Tablas 1 ,

Tabla 1

Distribución según hallazgo de L.F.

\begin{tabular}{ccr} 
& N. $^{\circ}$ de casos & Porcentaje \\
\hline Con leucocitos & 54 & 24.2 \\
\hline Sin leucocitos & 169 & 75.8 \\
\hline Total & 223 & 100 \\
\hline
\end{tabular}

2 y 3). Tampoco se encontraron diferencias en la frecuencia de enfermedades asociadas al ingreso $\mathrm{ni}$ adquiridas durante la hospitalización. 
Tabla 2

Distribución según sexo y edad

\begin{tabular}{ccccccccc}
\hline & \multicolumn{3}{c}{ Con leucocitos } & \multicolumn{3}{c}{ Sin leucocitus } & \multicolumn{2}{c}{ Total } \\
\hline & $\mathrm{V}$ & $\mathrm{M}$ & $\%$ & $\mathrm{~V}$ & $\mathrm{M}$ & $\%$ & $\mathrm{~N} .{ }^{\circ}$ & $\%$ \\
\hline $0 \mathrm{a} \mathrm{2 \textrm {m }}$ & 7 & 7 & 25.9 & 31 & 29 & 35.5 & 74 & 33.2 \\
\hline $3 \mathrm{a} 5 \mathrm{~m}$ & 9 & 7 & 29.7 & 31 & 26 & 33.7 & 73 & 32.7 \\
\hline $6 \mathrm{a} 11 \mathrm{~m}$ & 12 & 6 & 33.3 & 19 & 19 & 22.5 & 56 & 25.1 \\
\hline $12 \mathrm{momás}$ & 4 & 2 & 11.1 & 9 & 5 & 8.3 & 20 & 9.0 \\
\hline Total & 54 & 100 & & 169 & & 100 & 223 & 100 \\
\hline
\end{tabular}

Tabla 3

Distribuçión según estadus nutricional

\begin{tabular}{ccccr}
\hline & \multicolumn{1}{c}{$\begin{array}{c}\text { Con } \\
\text { Leuc. [\%]Leuc. [\%] }\end{array}$} & N. & $\%$ \\
\cline { 2 - 5 } Eutróficos & 27,8 & 31,3 & 68 & 30,5 \\
\hline D1 & 46,2 & 46,2 & 103 & 46,2 \\
\hline D2 & 20,4 & 14,8 & 36 & 16,1 \\
\hline D3 & 5,6 & 7,7 & 16 & 7,2 \\
\hline Total & 100 & 100 & 223 & 100
\end{tabular}

\section{Comparación de parumetros ctínicos (Tabla 4)}

La temperatura rectal examinada en el momento de la admisión al Servicio mostró diferencias estadísticamente significativas en todos los rangos analizados, observándose en el grupo con leucocitos una mayor acumulación de casos que ingresaron con fiebre e hipertermia y una mayor ocurrencia de ingresos afebriles en el grupo sin leucocitos $(\mathrm{p}<0,001)$.

El aspecto de las deposiciones se estudió considerando la presencia de mucus o sangre; las heces fueron calificadas por un mismo observador en el momento de extraer la primera muestra para la búsqueda de leucocitos. El análisis estadístico de estos datos demostró una proporción significativamente más alta de deposiciones con sangre o mucus en el grupo A $(p<0,001)$.
Tabla 4

Comparación de parámetros clínicos.

\begin{tabular}{|c|c|c|c|}
\hline & \multicolumn{2}{|c|}{ Con leuco. Sin leuco } & D \\
\hline \multicolumn{4}{|l|}{$\mathrm{T}^{0}[\mathrm{r}]$ al Ingreso } \\
\hline$\leq 37,5^{\circ}$ & 31.5 & 53.9 & $<005$ \\
\hline$>37,5^{\circ}$ & 68.5 & 46.1 & \\
\hline$\geq 39,0^{\circ}$ & 24,0 & 10.7 & $<001$ \\
\hline Mucus o sangre & 52 & 12 & $<001$ \\
\hline \multicolumn{4}{|l|}{ Desh. al Ingreso } \\
\hline Ausente & 18.5 & 24.3 & \\
\hline $4 \%$ y $<$ & 48.1 & 29.0 & $>05$ \\
\hline 5 a $9 \%$ & 24.0 & 36.1 & \\
\hline $10 \% \mathrm{y}>$ & 9.3 & 10.6 & \\
\hline \multicolumn{4}{|c|}{ Durac de la Hosp. } \\
\hline$\leq 7$ dias & $\mathrm{L} 5$ & 40 & $<001$ \\
\hline$>7$ dias & 85 & 60 & \\
\hline \multicolumn{4}{|l|}{ Bacteriolugía } \\
\hline Shighe!la & 18.5 & 1.18 & \\
\hline Salmonella & 7.4 & 0.59 & $<001$ \\
\hline Sin aislaum. & 50.0 & 42.8 & $>05$ \\
\hline
\end{tabular}

El porcentaje de ganancia de peso una vez corregida la deshidratación no reflejó variaciones significativas con el nivel de exigencias preestablecido $(p<0,05)$.

Atendiendo a la duración habitual de la estadía hospitalaria por Síndrome Diarreico Agudo no complicado, se comparó el porcentaje de casos de cada grupo cuya permanencia en el hospital fue 
de 7 o más días. La proporción fue significativamente más elevada en el grupo de enfermos con leucocitos en las heces $(\mathrm{p}<0,001)$.

Por último, se analizó la relación entre los leucocitos fecales $y$ la presencia de 3 enteropatógenos: Shighella, Salmonella y E. Coli (serotipos clásicos); se consideraron sólo los coprocultivos tomados durante la primera semana de hospitalización. Los dos primeros agentes aparecieron con una frecuencia significativamente superior en el grupo A; no se demostró variaciones en la distribución de los $\mathrm{E}$. Coli $(\mathrm{p}<0,001$ y $>0,05$ respectivamente).

\section{Evohucion de los leucoctios fecales (Figuras 1 y 2)}

En 41 pacientes que presentaron leucocitos en la muestra tomada al ingreso, se repitió diaria-

Figure 1

Evolución de los leucocitas fecales en 47 pacientes.

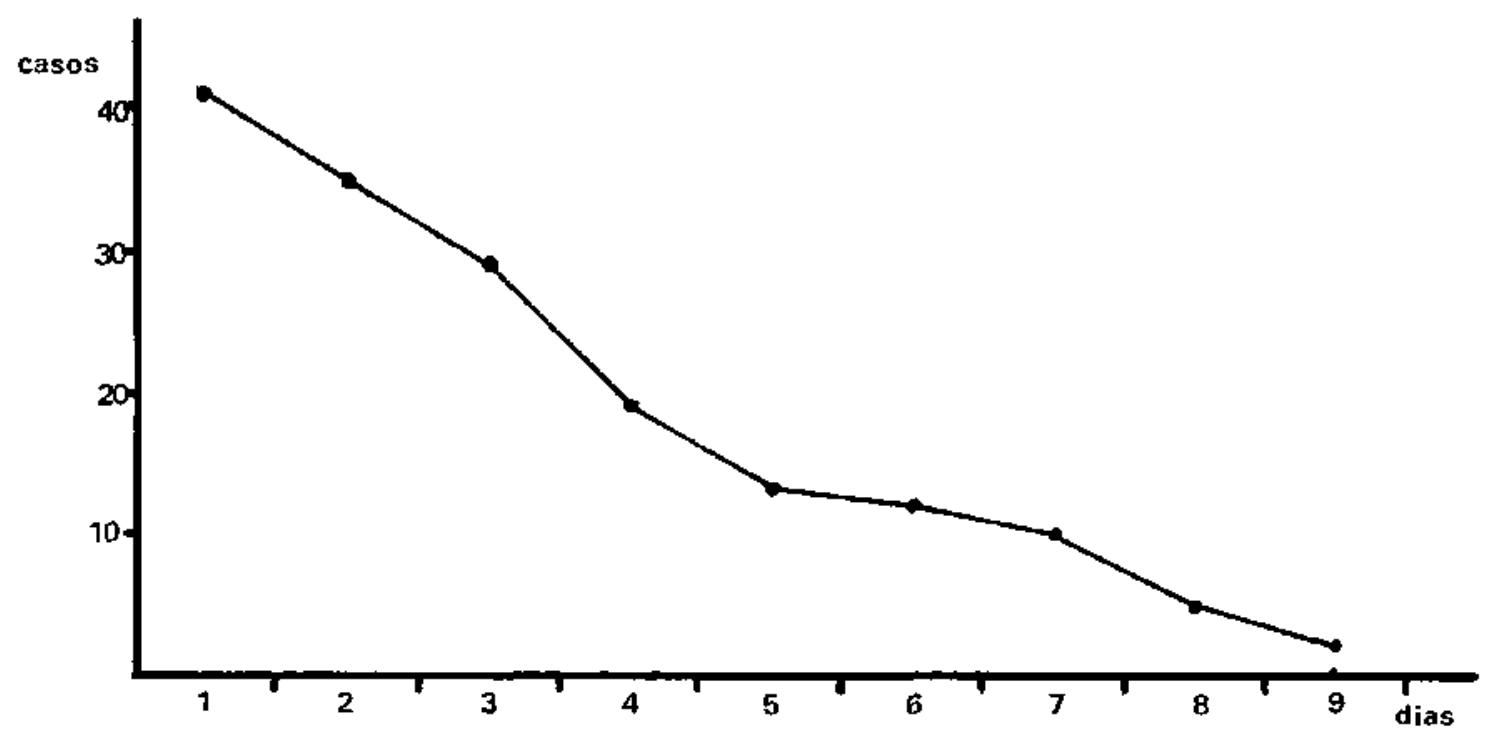

Figura 2

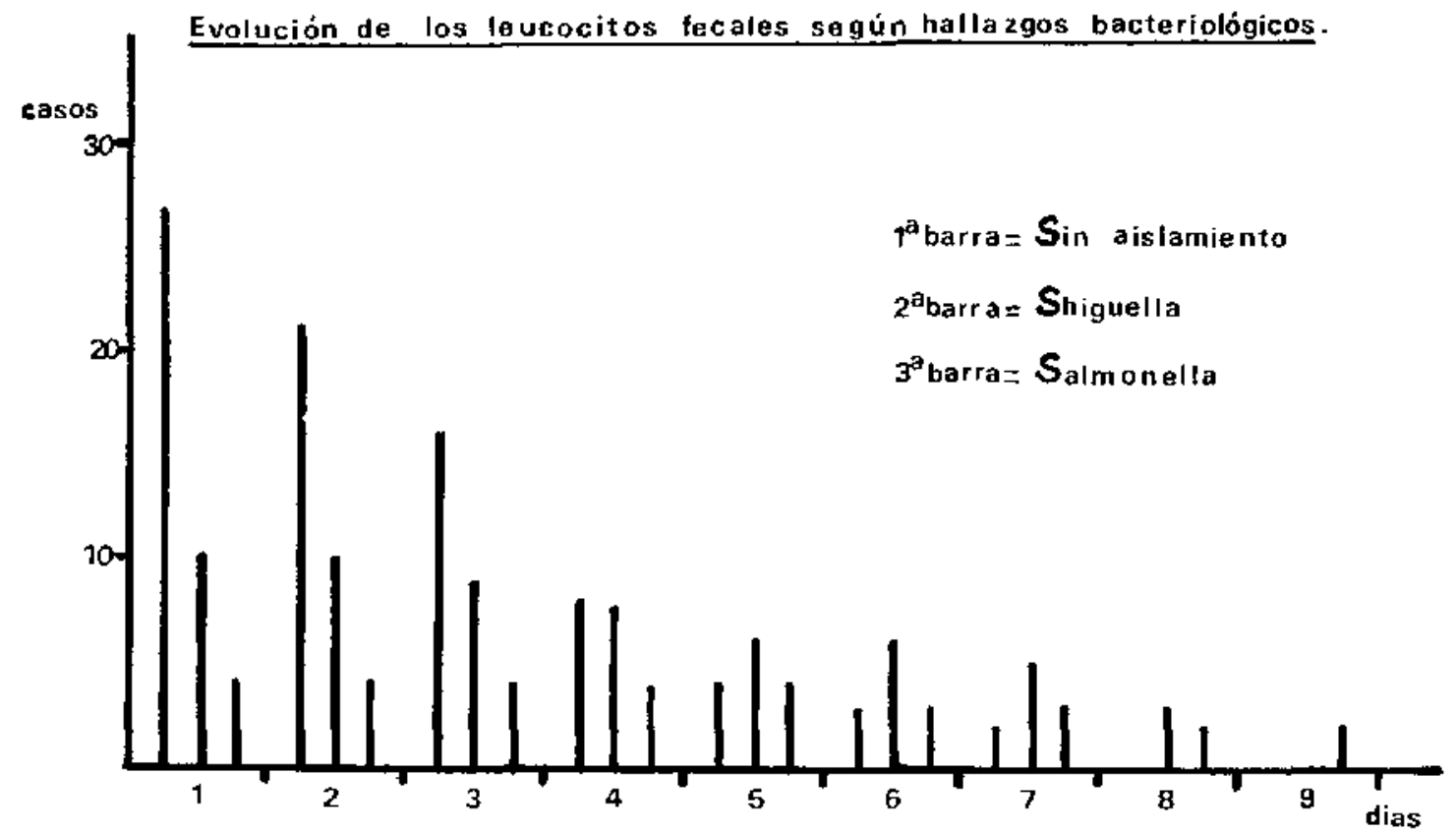


mente el examen hasta que se obtuvieron muestras negativas en 2 días sucesivos. Se observó que la duración máxima de leucocitos en las beces fue de 9 días. Cuando las muestras fueron separadas de acuerdo a su asociación o no con el aislamiento de algún enteropatógeno, se encontraron curvas más largas en los pacientes con Shiguella o Salmonella.

\section{Variabilidad del método}

Con el propósito de conocer la variabilidad del método usado para la investigación de leucocitos fecales, (por falsos negativos ofluctuaciones en la cantidad de células eliminadas por un mismo paciente), en 80 enfermos se repitió el examen en 3 oportunidades durante un mismo día, separadas por un lapso de 3 o 4 horas. Se comparó el porcentaje de casos positivos en las 3 series obtenidas, resultando una diferencia promedio de $1,25 \%$; la variación estuvo dada por un caso en que no se encontraron células en la segunda muestra, resultando positivas la primera y la tercera.

\section{CONCLUSIONES}

Pensamos que esta experiencia permite concluir que la eliminación de leucocitos en las heces durante el curso de un Síndrome Diarreico Agudo, representa para los enfermos afectados un mayor riesgo de evolucionar con fiebre e hipertermia, de tener mucus o sangre en sus deposiciones, de permanecer hospitalizados más de 7 dias y de estar infectados por un agente con capacidad invasora.

Creemos que la búsqueda rutinaria y precoz de leucocitos fecales en los pacientes con diarrea constituye un elemento que aporta una valiosa orientación etiopatogénica y pronóstica en esta entermedad.

\section{RESUMEN}

En 223 pacientes hospitalizados por diarrea en el Servicio de Lactantes del Hospital Roberto del
Río, se investigó la presencia de leucocitos en materia fecal y se correlacionaron los hallazgos conuna serie de parámetros clínicos y bacteriológicos.

La búsqueda fue positiva en 51 pacientes $(24,2 \%)$, encontrándose entre ellos una frecuencia significativamente mayor de casos con evolucion febril, con mucus o sangre en las deposiciones, con hospitalizaciones de más de 7 días y con aislamiento de Shiguella y Salmonella. No hubo diferencias en el comportamiento de la deshidratación, ni en la frecuencía de E. Coli - serotipos clásicos.

Se describe la técnica empleada para la investigación de células y los hallazgos resultantes del seguimiento diario efectuado en los casos positivos.

Se concluye que la investigación de Leucocitos Fecales en los enfermos con diarrea aporta una valiosa información etiopatogénica y pronóstica.

\section{REFERENCLAS}

${ }^{1}$ Willmore J.C., Sheamann Ch. On the diflerential diagnosis of dysenteries. The diagnostic value of cell-exudate in the stexol of acute amoebic and bacillary dysentery. Lancet 1: 51-55. 1918.

2 Larry K. Pickering, Herbert L. DuPons, Jorge Okwte, Richand Conkin, Charles Ersson. Fectal Leukocytes in Enteric Infections. Am I. Clin. Pathol, 68: 562-375, 1977.

3 Jahn C. Harts, Herber DwPont, Richard B. Homick Fecal Leukocytes in Diartheal Illness, Ann, on Int. Med. 76: 697-703. 1972.

tJame E. Peirce, Hertert DuPont, Kay R. Lewt. Acute Diarrhea in a residential Institution for the Feturded. Lisefulness of Fecal Lenkocyte Examination. Am. J. Dis. Child. 128: 772-775. 1974.

5 Angel Mercado, Mario Mem, Marja Eugenio Punto. Pesruisa de leucocitos fecales, en relación a diareas de etiologia bacteriana. Bol. Hosp. SJ. Dios 23: 186-93. 1976.

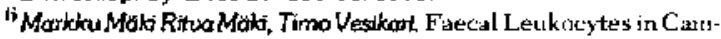
pylobacter-Associated Diarhoea in Intants. Actit Pediatr Scand 68: 271-272. 1979.

‘A. Salvo Castlito, Sankander, Gallo. S. Pediatría Hosp. J. Martinez Depto. Pediatria U. Catúlica de Chile. XIII Congreso Nacional Soc. Chil. Ped. Pucou - 1979.

${ }^{8}$ Pedro Coello Ramirea, S. Carios Mourin.Meleg, Stlufa Diaz-Bersussen. Estudio de] moco fecal en niños con diartea de evolución acouda o prolongada. Bol. Med. Hosp. Intant 33:61-78. 1976. 